\title{
Study of the Rostov nuclear power plant efficiency operation under increased vacuum value
}

\author{
Aleksey Babushkin ${ }^{1,2, *}$, Sergey Skubienko ${ }^{1}$, and Ludmila Kinash $^{1,2}$ \\ ${ }^{1}$ Platov South-Russia State Polytechnic University (NPI), Thermal Power Stations and Heat Transfer \\ Engineering Department, 346400 Novocherkassk, Russia \\ ${ }^{2}$ Academy of Construction and Architecture of Don State Technical University, Environmental \\ Engineering Department, 344000 Rostov-on-Don, Russia
}

\begin{abstract}
In this study, the influence of the cooling water temperature on the thermal efficiency of a conceptual pressurized-water reactor nuclearpower plant is studied. The change in the cooling water temperature can be experienced due to the seasonal changes in climatic conditions at plant site. The article presents the results of technical and economic parameters study of nuclear power unit's operation under increased vacuum value. Investigated seasonal variations of cooling water temperature, cooling water temperature influence on the vacuum temperature in the turbine condenser, and changing the basic technical and economic performance of nuclear power station. The mathematical model of calculation the nuclear power plant operation for a $1000 \mathrm{MW}$ power unit was developed.
\end{abstract}

\section{Introduction}

Nowadays, there are 10 nuclear power plants operating in our country (a total of 34 units of $25.2 \mathrm{GW}$ installed capacity), generating about $17 \%$ of all the electricity produced [1]. The main advantage of nuclear power plant over any other power plant is the independence from fossil fuel sources and low cost of electricity generation. The first nuclear reactor was invented in 1942 and was built according to the RBMK type (highpower channel reactor). In the course of the development of nuclear power, the capacity of nuclear reactors increased, so in 1973 the world's first reactor with a capacity of 1000 MW (RBMK - 1000) was launched and other types of reactors appeared [2].

Nowadays, all nuclear reactors are divided into 3 main types:

- HPCR - high-power channel reactor (single-circuit);

- PWPR - pressurized water power reactor (double-circuit);

- FN - fast neutron reactor (three-circuit).

The share of nuclear power generation is growing every year. In 1973, the share of nuclear power generation in the world was $3.3 \%$, and as of 2019 it is $10.6 \%$. However, despite all the advantages over other energy sources, NPPs have disadvantages associated

\footnotetext{
* Corresponding author: alekseybabushkinnpi@gmail.com
} 
with high capital costs during construction, the risk of emergencies with radiation contamination of the area, and a long payback period $[3,4]$.

Technically, the main disadvantage of the NPP is the low efficiency not exceeding $32 \%$. This is mainly due to low initial parameters of steam and losses of thermal energy in the condenser and other auxiliary systems of the NPP [5].

Recently, NPP power units in the summer time faced a new problem associated with an increased vacuum value in the condenser due to the high temperature of the cooling water. This problem is typical for nuclear power plants operating in the southern regions, where in summer the temperature of the cooling water can rise above 30 degrees centigrade [6-9].

\section{Influence of cooling water temperature on the NPP efficiency}

The cooling water temperature is one of the decisive factors in the power unit operation. The pressure in the turbine condenser depends on the temperature, consequently the process of steam expansion in the turbine, which undoubtedly affects the technical and economic performance of the power unit. The change in the cooling water temperature can be experienced due to the seasonal changes in climatic conditions at plant site. In the summer season, when the water temperature rises above 20 degrees, there is a serious change in the effect on the condenser parameters. Further increase of the cooling water temperature can lead to a serious reduction of the vacuum and the consequent increase in the primary steam flow and increasing fuel consumption $[5,6]$.

The research was carried out at the nominal operating parameters of a $1000 \mathrm{MW}$ power unit with steam turbine K-1000-60/1500 and VVER-1000 reactor shows on Figure 1 [7]:

- initial steam pressure $6 \mathrm{MPa}$;

- steam temperature $276{ }^{\circ} \mathrm{C}$

- condenser steam pressure $4 \mathrm{kPa}$.

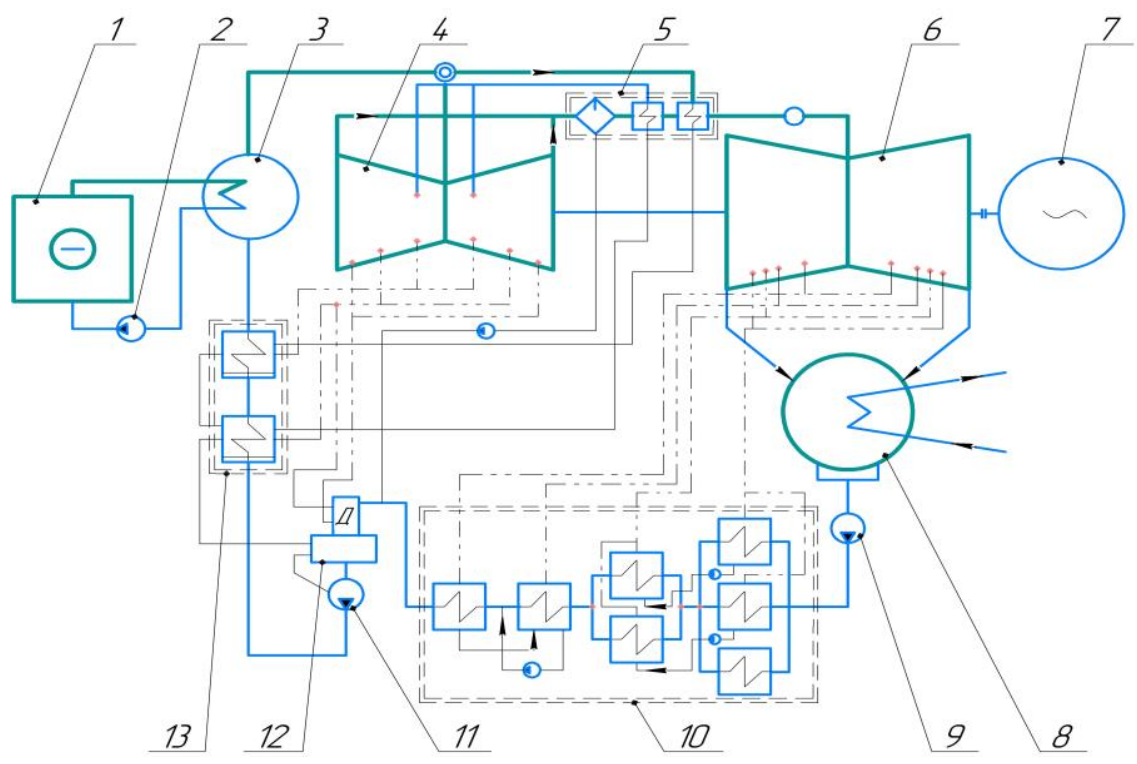

Fig. 1. K-1000-60-1500/2 KhTGP turbine plant:

1 - nuclear reactor; 2 - reactor coolant heater; 3 - steam generator; 4 - low-pressure cylinder; 5 steam superheater; 6 - high-pressure cylinder; 7 - generator; 8 - steam-turbine condenser; 9 condenser pump; 10 - network installation; 7 - ejector; 8 - supporting ejector; 9 - condensate pump; 10 - LPH group; 11 - turbine driven feed water pump; 12 - deaerator; 13 - HPH group. 
Figure 2 shows the change in the average temperature of cooling water by months of the year for a nuclear power plant located in the south of Russia in the city of Volgodonsk (Rostov NPP) [10-12].

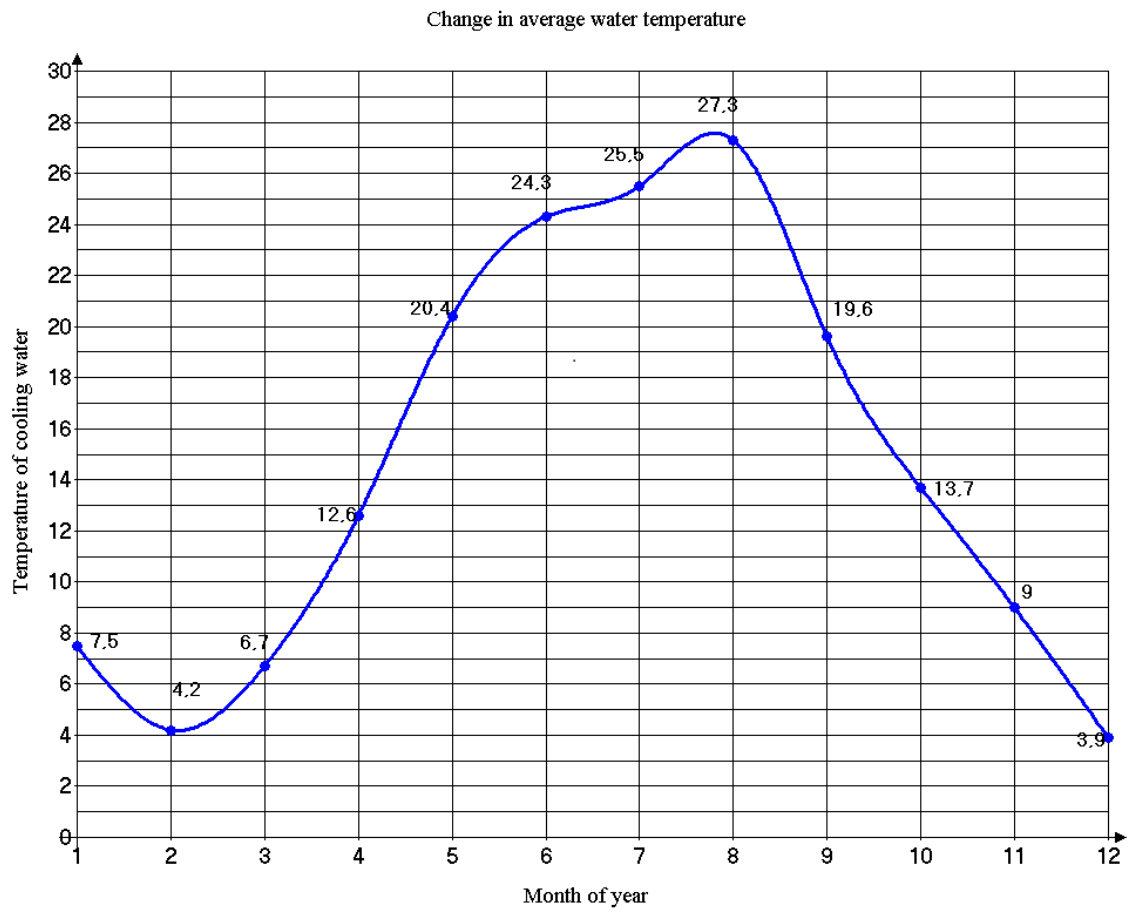

Fig. 2. The change in the cooling water temperature due to the seasonal changes

To carry out the research the mathematical model was developed implemented in the Mathcad software environment added by the WaterSteamPro 6.5 program to determine the parameters of steam and water for different pressure and temperature in different parts of technological scheme [13-15]. In the mathematical model NPP, when operating under rated load in accordance with these parameters, the greatest efficiency of the power unit is achieved, and the steam consumption for the turbine is $1580 \mathrm{~kg} / \mathrm{s}(1)$ :

$$
D_{0}=\frac{N_{\ni} \cdot 10^{3}}{\left(h_{0}-h_{\kappa}+\Delta h_{n n}\right) \eta_{\mu} \eta_{2} \eta_{\text {вэp }}}
$$

Accordingly, the passage of steam into the condensing unit is calculated by the formula (2) and is $840 \mathrm{~kg} / \mathrm{s}$ :

$$
D_{\kappa}=D_{0} \alpha_{\kappa}
$$

However, these characteristics are possible only provided that the temperature of the cooling water does not exceed the maximum value at which normal steam condensation is possible. The vacuum temperature at the normal value of the vacuum pressure is $29{ }^{\circ} \mathrm{C}$, corresponding to this temperature, taking into account the subcooling, the temperature of the cooling water at the output of the condensing unit is $26{ }^{\circ} \mathrm{C}(3)$ :

$$
t_{\text {ов } 2}=t_{\kappa . n}-\delta t
$$

Maximum performance of circulators pumps - 180000 ton $/ \mathrm{hr}$. When a critical temperature of $18.5^{\circ} \mathrm{C}$ is reached, circulation pumps cannot provide the required flow rate for steam condensation. In this case, in the warm season, the temperature and, accordingly, 
the vacuum pressure decrease, which leads to a decrease in the efficiency of the power unit operation (Table 1).

Figure 3 shows the change in the vacuum temperature in the condenser.

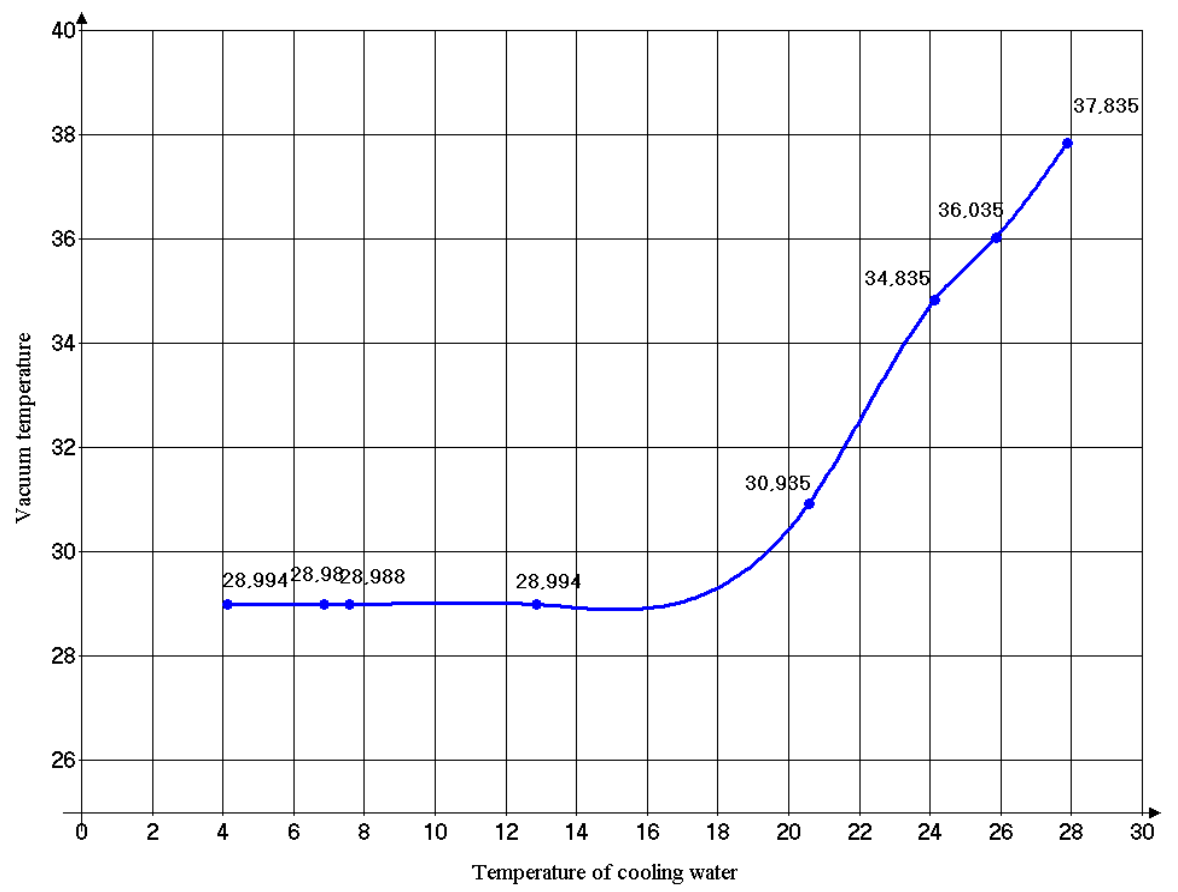

Fig. 3. Influence of the cooling water temperature on vacuum

Table 1. Change of technical and economic performance of nuclear power plants with the loss of vacuum in the condenser.

\begin{tabular}{|c|c|c|c|}
\hline Parameter & $\begin{array}{c}\text { Unit of } \\
\text { measurement }\end{array}$ & $\begin{array}{c}\text { Vacuum } \\
\text { temperature } \\
29{ }^{0} \mathrm{C}\end{array}$ & $\begin{array}{c}\text { Vacuum } \\
\text { temperature } \\
37,8^{0} \mathrm{C}\end{array}$ \\
\hline$Q_{t u}$ & $\mathrm{~kW}$ & 2845406 & 2962524 \\
\hline$q_{t u}$ & $\mathrm{~kJ} /\left(\mathrm{kW}^{*} \mathrm{~h}\right)$ & 10076,84 & 10484,59 \\
\hline$N_{e}^{t p p u m p}$ & $\mathrm{~kW}$ & 16534,94 & 17215,53 \\
\hline$\eta_{t u}$ & & 0,357 & 0,343 \\
\hline$\eta_{t u}^{e f f}$ & & 0,351 & 0,337 \\
\hline$Q_{s}$ & $\mathrm{~kW}$ & 2969677,356 & 3091910 \\
\hline$\eta_{p i p e}$ & & 0,958 & 0,958 \\
\hline$\eta_{s}^{b r}$ & & 0,326 & 0,313 \\
\hline$\eta_{s}^{\text {net }}$ & & 0,307 & 0,294 \\
\hline$b_{f u e l}^{n}$ & $\mathrm{~kJ} /\left(\mathrm{kW}^{*} \mathrm{~h}\right)$ & $1,75^{*} 10^{-7}$ & $1,83 * 10^{-7}$ \\
\hline
\end{tabular}


Temperature has a direct impact on the technical and economic performance of nuclear power plant. This effect is due to displacement of the end point of the expansion process and as a result, deterioration of performance of the unit under reduced pressure. For a more complete assessment of the temperature effect of the cooling water on the power unit operating parameters, it is necessary to conduct a deeper study for each point of change in the temperature head characteristics of condenser, as well as to conduct a study of technical and economic indicators in the entire range of vacuum change.

\section{Conclusion}

Taking into account the results obtained during the study of influence of cooling water temperature on the efficiency of $1000 \mathrm{MW}$ Rostov nuclear power plant, one can conclude as follows:

- upon reaching the temperature of the cooling water $18.5{ }^{\circ} \mathrm{C}$, the circulation pumps of the NPP power unit cannot cope with the load, as a result of which the vacuum temperature increases significantly;

- in summer time, especially in August, the vacuum temperature actually increases by $9{ }^{\circ} \mathrm{C}$ to $37.8^{\circ} \mathrm{C}$, which negatively effects on the NPP power unit efficiency;

- when the vacuum deteriorates, the technical and economic indicators are significantly reduced:

- net efficiency of the nuclear power unit is reduced by $1.2 \%$;

- specific consumption of equivalent fuel increases by $4.09 \%$;

- the absolute efficiency of the power unit is reduced by $1.39 \%$.

The article was prepared with the financial support of the Foundation For Assistance To Small Innovative Enterprises START №C1-81740. The grant holder - Aleksey Babushkin.

\section{References}

1. Zohuri, Bahman \& Mcdaniel, Patrick. (2019). Nuclear Power Plants. 10.1007/978-3319-93919-3_18.

2. Konstantin, Panos \& Konstantin, Margarete. (2018). Nuclear Power Plants. 10.1007/978-3-319-72305-1_4.

3. Ibrahim, Jamal. (2020). Nuclear power plant development. 10.1016/B978-0-12818483-7.00012-3.

4. Agar, Amritpal \& Locatelli, Giorgio. (2020). Economics of nuclear power plants. 10.1016/B978-0-12-818483-7.00004-4.

5. Kaur, Raminder. (2020). Kudankulam: The Story of an Indo-Russian Nuclear Power Plant. 10.1093/oso/9780199498710.001.0001.

6. Ahmet Durmayaz., Influence of cooling water temperature on the efficiency of a pressurized-water reactor nuclear-power plant, International Journal of Energy Research Volume 30(10), 5 December 2006, Pages 799 - 810

7. Technical and economic indicators of thermal power plants. 3rd ed., Revised. And add. M.: Energoatomizdat, Gorshkov A.S., 1988, 230s.

8. Popov R.V., Belov A.A. Skubienko S.V., STUDY OF THE EXCHANGEABLE COOLING WATER FLOW CONTROL OF EFFICIENCY AT CONDENSATION POWER PLANT (CPP), Energy saving and water treatment, 4, 32-28 (2018) 
9. Wu, P. \& Liu, X.-K \& Peng, M.-J. (2014). Modeling and simulation of nuclear power plant condenser. Yuanzineng Kexue Jishu/Atomic Energy Science and Technology. 48. 92-98. 10.7538/yzk.2014.48.01.0092.

10. Horvath, A., Rachlew, E. Nuclear power in the 21st century: Challenges and possibilities. Ambio 45, 38-49 (2016). https://doi.org/10.1007/s13280-015-0732-y

11. Ryzhkin V. Ya. Thermal power plants. 3rd ed.- M.: Energoatomizdat - 327 p.

12. Skubienko S., "Using an Absorption Heat Pump in the Regeneration System of Turbine Model K-300-240-2 Manufactured by Kharkov Turbo Generator Plant (KhTGP)," 2nd International Conference on Industrial Engineering, Applications and Manufacturing (ICIEAM) 2016

13. WaterSteamPro - registered program and trademark of Moscow Power Engineering Institute (Technical University) (http://www.mpei.ru)

14. Limar A., Skubienko S.V., Study of the technological and economic parameters dependence of a $300 \mathrm{MW}$ power plant on changes in the heating and electrical load, Lecture Notes in Electrical Engineering, 2020.

15. Mohamed M. A. Ibrahim., A Parametric Study of the Impact of the Cooling Water Site Specific Conditions on the Efficiency of a Pressurized Water Reactor Nuclear Power Plant, International Journal of Nuclear Energy, August 2014, Pages 1 - 6 